\title{
Novel metabolic and physiological functions of branched chain amino acids: a review
}

\author{
Shihai Zhang ${ }^{1,2}$, Xiangfang Zeng ${ }^{1 *}$, Man Ren ${ }^{3}$, Xiangbing Mao ${ }^{4}$ and Shiyan Qiao ${ }^{1}$
}

\begin{abstract}
It is widely known that branched chain amino acids (BCAA) are not only elementary components for building muscle tissue but also participate in increasing protein synthesis in animals and humans. BCAA (isoleucine, leucine and valine) regulate many key signaling pathways, the most classic of which is the activation of the mTOR signaling pathway. This signaling pathway connects many diverse physiological and metabolic roles. Recent years have witnessed many striking developments in determining the novel functions of BCAA including: (1) Insufficient or excessive levels of BCAA in the diet enhances lipolysis. (2) BCAA, especially isoleucine, play a major role in enhancing glucose consumption and utilization by up-regulating intestinal and muscular glucose transporters. (3) Supplementation of leucine in the diet enhances meat quality in finishing pigs. (4) BCAA are beneficial for mammary health, milk quality and embryo growth. (5) BCAA enhance intestinal development, intestinal amino acid transportation and mucin production. (6) BCAA participate in up-regulating innate and adaptive immune responses. In addition, abnormally elevated BCAA levels in the blood (decreased BCAA catabolism) are a good biomarker for the early detection of obesity, diabetes and other metabolic diseases. This review will provide some insights into these novel metabolic and physiological functions of BCAA.
\end{abstract}

Keywords: Amino acid transporters, Glucose transporters, Gut health, Immunity, Lipolysis, Mammary health, Meat quality, Milk production

\section{Background}

The branched chain amino acids (BCAA: leucine, isoleucine, and valine) are essential amino acids and must be obtained from the diet. BCAA not only act as building blocks for tissue protein (accounting for 35\% of the essential amino acids in muscle) [1], but also have other metabolic functions [1]. Among the three BCAA, leucine earns the greatest reputation for its specific function in activation of the mTOR signaling pathway. Since the 1970s, the role of leucine in enhancing protein synthesis has been reported both in vitro and in vivo [2, 3]. More recently, BCAA have been extensively used as performance-enhancing supplements for body builders and fitness enthusiasts $[4,5]$. Besides playing a vital role

\footnotetext{
* Correspondence: zengxf@cau.edu.cn

${ }^{1}$ State Key Laboratory of Animal Nutrition, College of Animal Science and Technology, China Agricultural University, No.2 Yuanmingyuan West Road, Haidian District, Beijing 100193, People's Republic of China

Full list of author information is available at the end of the article
}

in protein metabolism, a variety of physiological and metabolic functions have been reported for BCAA. For instance, BCAA were reported to increase the secretion of insulin [6]. However, increased level of plasma BCAA have also been reported to lead to insulin resistance or type 2 diabetes mellitus. One possible mechanism for this is that persistent activation of mTOR signaling pathway uncouples the insulin receptor from insulin receptor substrate 1 [7]. Another possible mechanism is accumulation of toxic BCAA metabolites (caused by abnormal BCAA metabolism) may trigger mitochondrial dysfunction which is associated with insulin resistance [8].

More recently, BCAA have been reported to participate in lipolysis, lipogenesis, glucose metabolism, glucose transportation, intestinal barrier function and absorption, milk quality, mammary health, embryo development, and immunity [9-14]. In addition, levels of BCAA in the body can act as a biomarker for the early detection of chronic diseases in humans [15]. The 
main objective of this review is to provide insights into new developments in BCAA research as well as their implications for both animal husbandry and human health.

\section{Metabolism of BCAA}

The metabolism of BCAA is well established. However, this should be addressed before we start looking into the detail functions of BCAA as this can provide the reader with a better understanding of this paper. BCAA are not degraded directly in the liver and most of them are available for metabolism in skeletal muscle and other tissues. However, the liver can oxidize BCAA after they are converted into $\alpha$-ketoacids in other tissues [16]. The main steps of BCAA catabolism are listed below (Fig. 1). Firstly, with the participation of branched-chain aminotransferase (BCAT), BCAA are converted into branchedchain $\alpha$-ketoacids (leucine to $\alpha$-ketoisocaproate, valine to $\alpha$-ketoisovalerate, and isoleucine to $\alpha$-keto- $\beta$-methylvalerate) by removing their amino group. Subsequently, branched-chain $\alpha$-ketoacids are decarboxylated by branched-chain $\alpha$-ketoacid dehydrogenase (BCKD). Finally, these BCAA metabolites are catabolized by a series of enzyme reactions to final-products (acetyl-CoA from leucine, succinyl-CoA from valine, and both acetyl-CoA and succinyl-CoA from isoleucine), which enter the TCA cycle.

\section{BCAA and fatty acid metabolism}

In humans, consumption of diets with an increased protein and reduced carbohydrate content enhances weight loss with greater loss of body fat and less loss of lean body mass $[17,18]$. In recent years, BCAA have been considered as novel therapeutic tools for controlling obesity and its related metabolic disorders, such as diabetes and insulin resistance, by enhancing exercise performance, regulating the composition of body protein and its properties, and controlling glucose tolerance, which are all related to improved health and fitness [16].

Studies in mice have indicated that diet-induced obesity mice in an isoleucine treatment (final concentration of $2.5 \%$ isoleucine in drinking water) had almost $6 \%$ lower body weight gain and $49 \%$ less epididymal white adipose tissue mass compared with the control treatment, with higher levels of hepatic protein CD36/fatty acid translocase, PPAR $\alpha$, and uncoupling protein (UCP) 2 and muscular levels of UCP3 [13]. Similarly, when dietary energy was restricted, leucine supplementation was found to increase fat loss and enhance muscle protein synthesis [19].

Interestingly, several studies have reported that supplying animals with a BCAA deficient diet increased lipolysis. Studies in mice discovered that feeding a leucine-deficient diet for $7 \mathrm{~d}$ suppressed lipogenesis in the liver [20] and also increased fat lipolysis in white adipose tissue [21]. Furthermore, isoleucine or valine deprivation also induced fat mass loss in mice [22]. Similarly, in female broiler chickens, low dietary BCAA levels reduced fatty acid synthesis and enhanced fatty acidoxidation by up-regulating hepatic lipogenic gene ACC $\alpha$ and SCD-1 expression (ACC $\alpha$ is the enzyme for carboxylation of acetyl-CoA to malonyl-CoA which is the

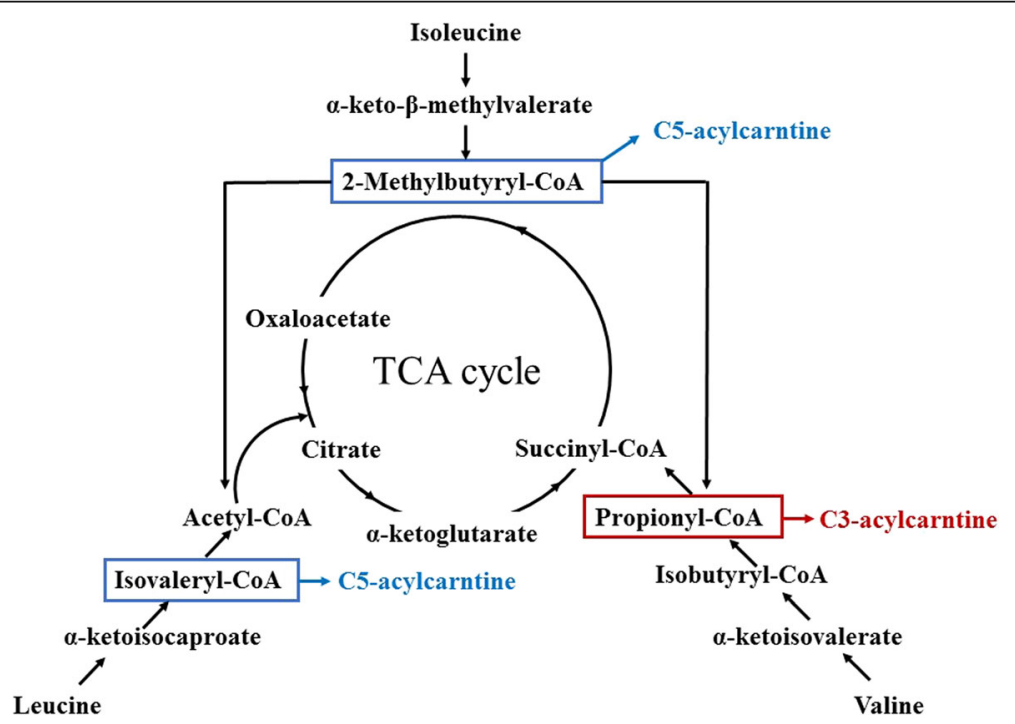

Fig. 1 Pathway of branched chain amino acid catabolism. BCAA are catabolized to acetyl-CoA and/or succinate-CoA and subsequently enter the TCA cycle. The main steps of the catabolic reactions (transamination by BCAT and decarboxylation by BCKD) are shown. With the help of BCAT, BCAA are catabolized into branched-chain a-ketoacids which are subsequently decarboxylated by BCKD. Finally, all the BCAA metabolites are catabolized by a series of enzyme reactions to final products and enter the TCA cycle 
rate-limiting step for both synthesis and elongation of fatty acid synthesis while SCD-1 catalyzes the biosynthesis of monounsaturated fatty acids from dietary lipids) without affecting growth performance, and is likely mediated through the AMPK-mTOR-FoxO1 pathway [23].

A possible mechanism of a BCAA deficient diet in enhancing lipolysis is the activation of the GCN2 pathway. It was demonstrated that a leucine deficient diet resulted in reduction of food intake and weight lost in both $\mathrm{GCN}_{2}^{+/+}$and $\mathrm{GCN}^{-/-}$mice, but only resulted in loss of liver mass and abdominal adipose mass in GCN2 ${ }^{+/+}$mice [20].

Taken together, both insufficient or excessive levels of BCAA in the diet could be detrimental to lipid metabolism. Supplementation of BCAA increased acetyl CoA levels in cells which subsequently inhibited the activity of pyruvate dehydrogenase. The preference for the cellular energy source was shifted from carbohydrate to lipid. Also, BCAA up-regulates hepatic fatty acid translocation and fatty acid oxidation gene expression [13]. Compared with BCAA supplementation of the diet, feeding animals with a BCAA deficient diet dramatically reduces food intake by activating the GCN2 signaling pathway, which might participate in lipolysis (down-regulating lipogenesis genes or up-regulating lipolysis genes) in the liver and adipose tissue. At present, studies focusing on fatty acid metabolism are limited. Although some contradictions exist among different studies, the intimate relationship between BCAA metabolism and fatty acid metabolism cannot be denied and more research is needed in the future to explore these relationships.

\section{BCAA and glucose transportation}

Accumulating evidence indicates a strong connection between amino acids and plasma glucose levels [24]. Branched chain amino acids have been demonstrated to strongly enhance glucose consumption and utilization [14]. In an animal oral glucose tolerance test, both isoleucine and leucine prevented a rise in plasma glucose concentrations, and the effect of isoleucine was greater than the other BCAA [14]. In a $\mathrm{C} 2 \mathrm{C} 12$ myotubes experiment, both leucine and isoleucine stimulated glucose uptake [14]. Nishitani et al. [25] and Doi et al. [26] observed similar results showing that isoleucine participated in plasma glucose uptake in the rat. A hypothesis for the mechanism through which isoleucine and leucine regulate the serum glucose levels might be due to an increase in muscle glucose uptake, whole body glucose oxidation and a decrease in hepatic gluconeogenesis [27].

The fact that BCAA enhance glucose uptake with activation or up-regulation of glucose transporters has been widely demonstrated $[14,25]$. Leucine increases glucose uptake by up-regulating the translocation of GLUT4 and GLUT1 in rat muscle [25]. Similarly, another experiment reported that leucine enhances the expression of GLUT4 glucose transporter and 2-deoxyglucose uptake in C2C12 cells [14]. Scientists suggest two hypotheses to interpret the mechanism through which leucine regulates muscular glucose transporters. Firstly, leucine enhances translocation of GLUT1 and GLUT4 by upregulating insulin levels [28-30]. Secondly, leucine increases glucose uptake in skeletal muscle via the PI3K and PKC signaling pathways [14] both of which are associated with GLUT4 translocation [31].

Compared with leucine, research focusing on the mechanism through which isoleucine acts is limited. Recent studies done in our lab demonstrate that feeding weanling pigs an isoleucine deficient diet down-regulates the protein expression of GLUT1 in red muscle and GLUT4 in red muscle, white muscle and intermediate muscle (Fig. 2) [32]. Furthermore, our experiments showed that an isoleucine deficient diet suppresses the expression of intestinal glucose transporter SGLT-1 in the duodenum, jejunum and ileum and GLUT2 in the duodenum and jejunum (Fig. 2). The function of isoleucine in enhancing glucose uptake and muscular glucose transporter expression (GLUT1 and GLUT4) was also demonstrated in $\mathrm{C} 2 \mathrm{C} 12$ myotubes in our study. However, the underlying mechanisms through which it functions are still unknown.

Collectively, BCAA regulate the expression and translocation of muscular or intestinal glucose transporters through insulin-dependent or insulin-independent ways. These findings have important implications in that BCAA could enhance muscle growth and intestinal development by increasing the local glucose uptake for animals and humans.

\section{BCAA and protein synthesis}

Since 1999, Joshua C. Anthony, the pioneer in leucine functional research, conducted a series of experiments regarding the effects of leucine on muscle protein synthesis and its underlying mechanisms (Fig. 3). Firstly, his team observed that leucine stimulates the recovery of skeletal muscle protein synthesis after exercise, independent of increased plasma insulin [33]. Their studies also revealed that leucine enhances muscle protein synthesis via the mammalian target of rapamycin (mTOR) pathway leading to phosphorylation of its downstream target proteins, eukaryotic initiation factor 4E-binding protein (4E-BP1) and p70 ribosomal S6 kinase 1 (S6K1) $[34,35]$. Since then, many experiments have been conducted which strongly support their results $[5,36]$. Leucine has been shown to stimulate muscle protein synthesis in rats [19, 37, 38], pigs [39-41] and humans [5, 42, 43]. The team of Teresa A. Davis evaluated the 


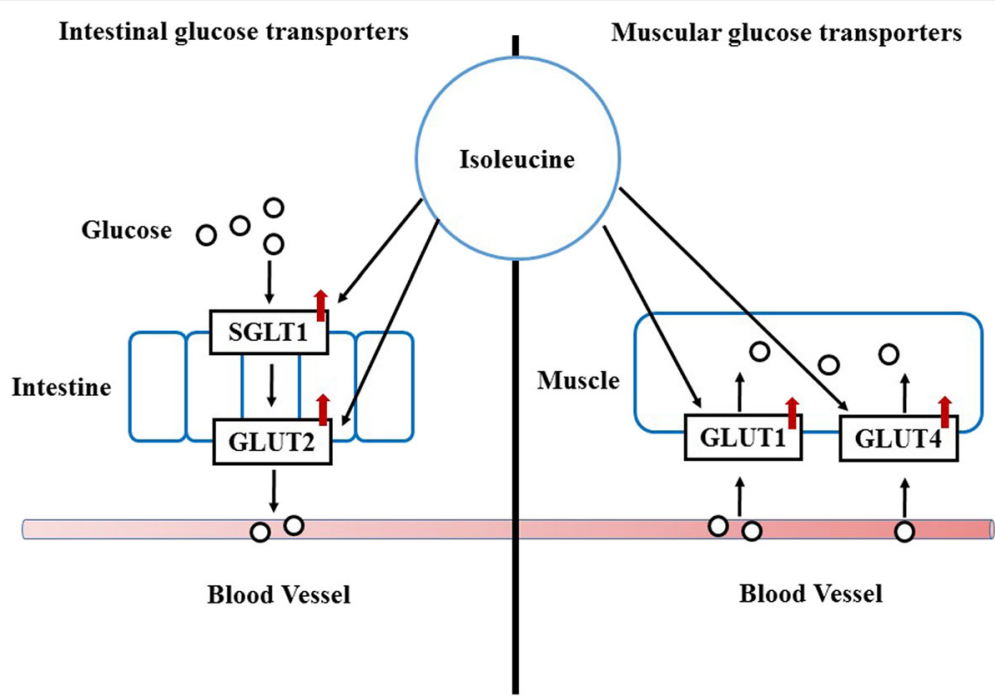

Fig. 2 Isoleucine up-regulates intestinal and muscular transporters. GLUT1 and GLUT4 are vital glucose transporters in muscle. SGLT1 and GLUT2 are important glucose transporters in the small intestine. Isoleucine could potentially increase muscle growth and intestinal development and health by up-regulating the protein expression of GLUT1 and GLUT4 in muscle and enhancing the expression of SGLT1 and GLUT2 in the small intestine

function of leucine in neonates. They found leucine has unique anabolic properties and the supplementation of leucine or its metabolites $\alpha$-ketoisocaproic acid and $\beta$-hydroxy- $\beta$-methylbutyrate strongly increase muscle protein synthesis in neonates [44-46]. Supplementation of leucine in a protein deficient diet had a strong positive connection to protein synthesis [47]. Interestingly, some studies reported that supplementation of leucine in a chronically restricted protein and energy diet only enhanced mTOR pathway activation without increasing

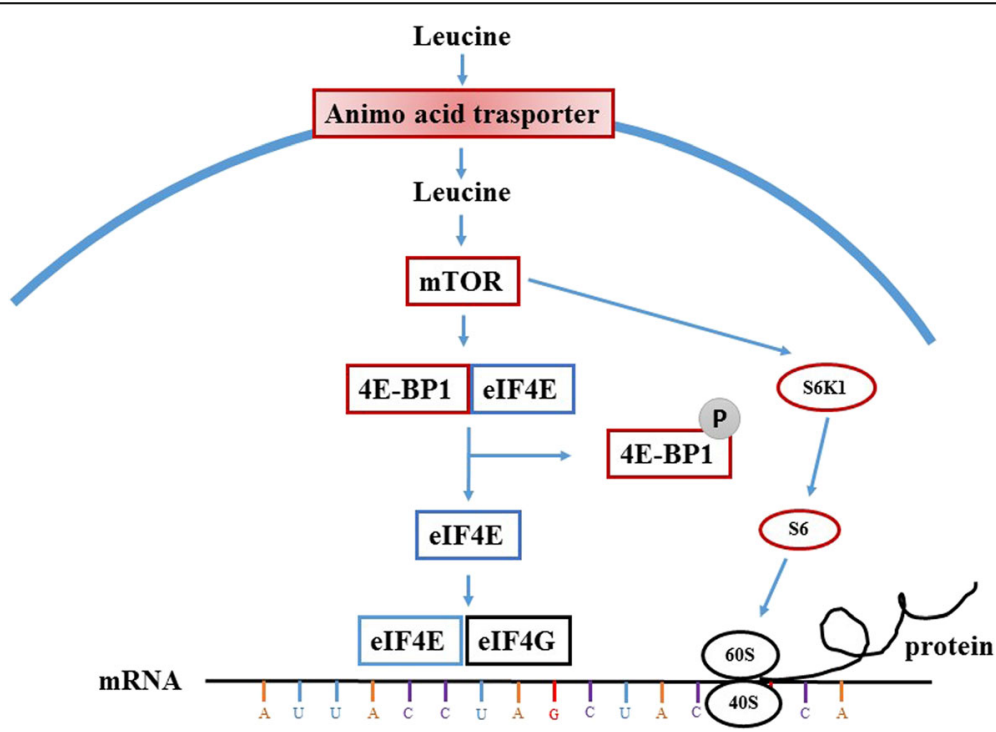

Fig. 3 Leucine increases protein synthesis by activation of the mTOR signaling pathway. Leucine enhanced muscle synthesis via the mammalian target of rapamycin (mTOR) pathway leading to phosphorylation of its downstream target proteins, eukaryotic initiation factor 4E-binding protein (4E-BP1) and p70 ribosomal S6 kinase 1 (S6K1). Under unphosphorylated conditions, 4EBP1 tightly binds to elF4E, forming the inactive elF4E. $4 E B P 1$ complex. During anabolic conditions, mTORC1 induces the phosphorylation of 4EBP1, resulting in the dissociation of elF4E from the inactive complex and allowing elF4E to form an active complex with elF4G. The process of association of elF4E with elF4G is obligatory for the binding of the 435 pre-initiation complex with mRNA. S6K1 is another mTORC1 substrate that participates in the regulation of mRNA translation. This kinase plays an important role in the regulation of terminal oligopyrimidine mRNA which is responsible for the translation of proteins involved in the protein synthetic apparatus 
muscle protein synthesis in neonatal pigs [48]. This indicates that the stimulation of protein synthesis by leucine is dependent on the availability of other amino acids [49].

Recently, the synergistic effect between leucine and leptin, and the effect of leucine on meat quality has been reported by our lab. In our study, we found that leucine stimulated the expression of leptin and its muscular receptor [50]. In addition, the combination of leptin and leucine synergistically regulated protein metabolism in skeletal muscle both in vitro and in vivo [51]. In an experiment with finishing pigs, we found that supplementation with leucine $(1.25 \%)$ could enhance pork texture by enhancing protein deposition and improving meat quality [52]. Similarly, another experiment in finishing pigs reported that leucine addition increased juiciness accompanying the increase in intramuscular fat content occurring with a protein deficient diet [53]. However, supplementation of excess leucine $(3.75 \%)$ in the diet changes plasma amino acid-derived metabolites, which may limit the use of high Leu diets to treat muscle atrophy [54]. Therefore, a high dose of leucine could be toxic and finding a suitable supplementation level of leucine is vital for future use.

In conclusion, the effect of leucine in increasing protein synthesis via the mTOR signaling pathway is widely known, the function of which might be enhanced by leptin. A reasonable supplementation level for leucine could improve meat quality.

\section{BCAA and feed intake}

The function of central leucine infusion on feed intake inhibition has been demonstrated in many studies $[55,56]$. The mTOR signaling pathway plays a vital role in the brain to detect nutrient availability and regulate energy balance [57]. In an experiment with rats, Cota et al. [57] demonstrated that mTOR signaling is controlled by energy status in specific regions of the hypothalamus and colocalizes with neuropeptide $\mathrm{Y}$ and proopiomelanocortin neurons in the arcuate nucleus. However, the function of leucine on feed intake is different when leucine is supplied in the diet. Many experiments demonstrated that extra supplementation of leucine in the diet not increase feed consumption in animals [58-61]. The divergent results caused by oral or central leucine supplementation might be explained by the capacity of leucine to cross the bloodbrain barrier and reach the central neural system.

Although extra supplementation of BCAA in the diet does not further increase the feed intake, the function of a BCAA-deficient diet in down-regulating feed intake can not be ignored. Gloaguen et al. [62] conducted a trial to test if feed intake was affected after ingestion of Val- and $\mathrm{Val}+$ diets with an excess of Leu. They found that prior ingestion of the Val- test diet resulted in a $14 \%$ reduction in feed intake compared with Val + test meal. Zhang et al. [63] reported that feeding piglets with $17 \%$ crude protein BCAA-deficient diet significantly decreased feed intake by $42 \%$. As BCAA are essential amino acids for animals, the reduction of feed intake could be interpreted as a function of the unbalance essential amino acid levels in the serum, which are regulated with the activation of GCN2 signaling pathway [64].

\section{BCAA and mammary function}

A significantly increased whole-body BCAA catabolism has been observed during lactation compared with nonlactating counterparts $[65,66]$. BCAA catabolism could enhance the syntheses of glutamate, glutamine, aspartate, alanine, and asparagine in the mammary gland and increase the production of milk for suckling neonates $[11,12]$. In addition, the major leucine transporter LAT1 is a limiting factor for the synthesis of glutamate and aspartate in mammary tissue [67]. Concurrently, the activity of BCAT and BCKD (two vital enzymes in BCAA catabolism) are increased in mammary tissue during lactation [68], which might be caused by reductions in insulin and growth hormone or increases in cortisol and glucagon [69].

Accumulating evidence indicates the obvious connection among BCAA, milk production and neonatal piglet performance. An experiment in sows demonstrated that supplementation of BCAA in the diet (Control group: $16 \% \mathrm{CP}$ vs. Treatment group: $23 \% \mathrm{CP}+\mathrm{BCAA})$ increased milk protein secretion but not milk yield [70]. In early lactation in fistulated dairy cows, compared with abomasally infused EAA ones, omission of leucine or BCAA decreased protein yield about $12 \%$ and $21 \%$, respectively [71]. A recent study found that increasing the total dietary Val:Lys ratio from 0.84:1 to $0.99: 1$ increased milk concentrations of isoleucine and valine [72]. These results indicate that the level of BCAA (especially leucine) in the diet plays a vital role in determining milk protein percentage. The underlying mechanism for a deficiency of BCAA impairing milk protein production is due to the deactivation of mTORC1-mediated upregulation of eIF2B $\varepsilon$ and eIF2 $\alpha$ abundance [73]. However, another $2 \times 2 \times 2$ factorial study in sows (two levels of valine (0.80 and $1.20 \%)$, isoleucine (0.68 and $1.08 \%)$, and leucine (1.57 and 1.97\%)) found that only supplementation of valine tended to increase milk nitrogen, but not isoleucine or leucine [74]. For neonatal piglets, this research found that increasing dietary valine level from $0.8 \%$ to $1.2 \%$ in sows is vital for increasing litter weaning weight [74].

The function of BCAA on milk production might be manipulated via the mammary cells (Fig. 4). In mammary epithelial cells, BCAA could stimulate their growth and proliferation, enhance their functional differentiation and 


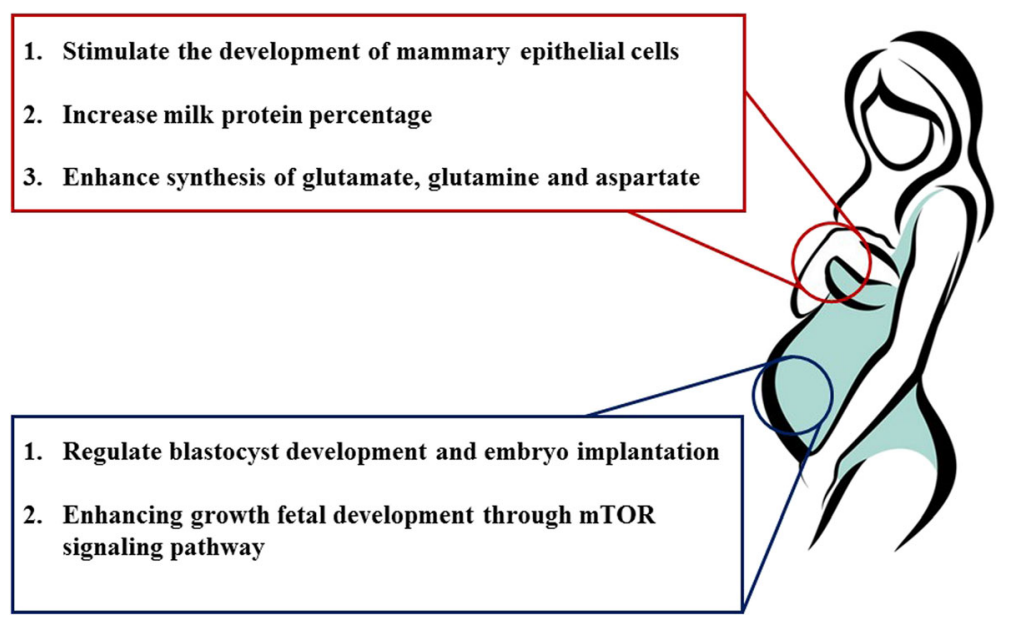

Fig. 4 Branched chain amino acids regulate mammary function and embryo development. BCAA play a vital role in mammary function and embryo development mainly in the synthesis of other conditional amino acids and activation of the mTOR signaling pathway

increase their longevity [75]. Both leucine and isoleucine have been shown to enhance the fractional protein synthesis rates in bovine mammary cells with the phosphorylation of mTOR and rpS6, or mTOR, S6K1, and rpS6 respectively [76], while decreasing the abundance of proteasome protein, ubiquitinated protein, and the rate of protein degradation [77]. The mechanism through which valine functions is still unknown.

These novel findings not only advance our understanding of BCAA regulation of lactation but also provide a new strategy to improve milk production by livestock and humans.

\section{BCAA, blastocyst development and fetal growth}

Early embryo growth and development of the fetus depend entirely on maternal nutrition. Alterations in fetal health are strongly associated with the development of chronic diseases later in adult life [78]. BCAA have been implicated as one of the vital elements in fetal development. Compared with women with healthy fetuses, pregnant women with fetuses with intrauterine growth retardation (IUGR) have lower plasma concentrations of BCAA in the umbilical artery and vein [79]. Protein synthesis is important for early embryo development. Among all the BCAA, leucine is the most important as it stimulates protein synthesis in skeletal muscle and other tissues through the mTOR signaling pathway [80]. Supplementation of BCAA (1.8\% L-Leu, 1.2\% L-Val, and $1 \%$ L-Ile) relieves IUGR syndrome induced by a lowprotein maternal diet through activation of the mTOR signaling pathway [10]. Furthermore, a BCAAsupplemented diet is reported to improve the gene and protein expression of IGF-1 and IGF-2 in fetal liver which could ameliorate fetal growth restrictions [79]. However, another study found L-leucine (at doses of 300 or $1,000 \mathrm{mg} / \mathrm{kg}$ body weight) administered orally during organogenesis did not affect the outcome of pregnancy. in rats [81]. The conflict in results might be caused by different dietary leucine concentrations and BCAA combinations. It is apparent that leucine up-regulates fetal growth by the enhancement of protein synthesis and secretion of hormones.

Besides being necessary for the development of the embryo, amino acids enhance embryo implantation by improving blastocyst quality. Researchers have found that amino acids are necessary for cultivating mouse embryos in vitro [82] which might be because of the embryonic requirement for AA as basic nutrients. Subsequently, amino acids are proved to induce trophectoderm motility and mouse embryo implantation via activation of the mTOR signaling pathway [83-85]. As one of the most vital roles for leucine is activating the mTOR signaling pathway, this indicates that leucine might participate in blastocyst development. Recently, it has been reported that up-regulation of leucine transporter SLC6A14 induces blastocyst activation [86, 87]. All this evidence indicates that leucine has an important function in blastocyst development. However, the optimal levels of BCAA required during pregnancy and lactation for animals and humans are still unknown.

\section{BCAA and gut function}

In addition to glutamine and asparagine, large amounts of BCAA are consumed and oxidized in the intestine. BCAA were catabolized in jejunal mucosal cells with a high activity of cytosolic BCAT and about $30 \%$ of the BCAA-derived branched-chain $\alpha$-ketoacid were decarboxylated by BCKD $[88,89]$. Several studies have found that BCAA participates in intestinal amino acid transporter expression [90]. Supplementing $1.4 \mathrm{~g}$ L-leucine/ 
$\mathrm{kg}$ body weight to breast-fed neonates improves intestinal development and increases the expression of neutral amino acid transporters $\left(\mathrm{ATB}^{0,+}, \mathrm{B}^{0} \mathrm{AT} 1\right.$ and $\left.\mathrm{b}^{0,+} \mathrm{AT}\right)$ [90]. In a study conducted in our lab, we demonstrated that meeting BCAA requirement (supplementing $0.1 \%$ L-Leu, $0.34 \% \mathrm{~L}-\mathrm{Val}$, and $0.19 \% \mathrm{~L}-\mathrm{Ile}$ in $17 \%$ crude protein diet) is necessary for maintaining intestinal health and amino acid transporter expression [63], the latter of which might be through the PI3K/Akt/mTOR and ERK signaling pathways [91]. Interestingly, we found that leucine not only increased the expression of neutral amino acid transporters (ASCT2, rBAT and 4F2hc), but also cationic amino acid transporters (CAT1) which emphasizes the importance of BCAA in intestinal nutrient absorption.

Besides regulating intestinal amino acid transporter expression, BCAA also have an intimate connection with other intestinal functions. Elevating dietary leucine level from $1.37 \%$ to $2.17 \%$ enhanced the intestinal development of broilers through the mTOR signaling pathway [92]. Concurrently, Mao et al. [93] demonstrated that extra dietary $1 \%$ leucine supplementation alleviated a decrease in mucin production and goblet cell numbers in the jejunal mucosa of weaned pigs, which possibly occurs via activation of mTOR signaling. Similarly, the role of leucine (increasing leucine level from $0.71 \%$ to $1.33 \%$ ) in maintaining gut health (enhancing tight junction) was also demonstrated in fish [94].

BCAA can be utilized by bacteria in the lumen of the gut [95]. Based on the 24-h disappearance rates of amino acids in different intestinal segments, Dai et al. [95] divided AA into three groups (high, medium or low disappearance rate groups), and found that leucine belongs to the high disappearance rate group while isoleucine and valine belong to the medium disappearance rate group. This is important evidence that BCAA participate in bacterial metabolism indicating they might participate in the regulation of intestinal microbial species and diversity. More research needs to be done to elucidate the detailed changes in these microbial species.

Collectively, most of the studies still focus on the functions of leucine but not valine or isoleucine in the intestine. However, the high expression of BCAT and BCKT in the intestine indicates the strong connection between $\mathrm{BCAA}$ and intestinal function.

\section{BCAA and immune function}

People noticed the effects of BCAA on the immune system $10 \mathrm{yr}$ ago because immune cells oxidize BCAA as fuel sources and incorporate BCAA as the precursors for the synthesis of new immune cells, effector molecules, and protective molecules [9]. Lack of BCAA in the diet impairs many aspects of immune function and increases susceptibility to pathogens. A recent study showed that a daily $12 \mathrm{~g}$ BCAA oral supplementation improved phagocytic function of neutrophils and NK activity of lymphocytes in cirrhotic patients [96]. After a BCAA enriched solution was infused into patients with rectal cancer, their immune status was improved with increased CD4+, CD4+/CD8+ and IL-2R [97]. Similarly, $12 \mathrm{~g} / \mathrm{d}$ of BCAA (6 g/d L-Leu, $2 \mathrm{~g} / \mathrm{d}$ L-Iso and $4 \mathrm{~g} / \mathrm{d} \mathrm{L}$-Val) supplementation blunted the neutrophil response to intense cycling training, which might benefit immune function during a prolonged cycling season [98]. In animal husbandry, supplementing BCAA (0.1\% L-Leu, $0.34 \% \mathrm{~L}-\mathrm{Val}$, and $0.19 \% \mathrm{~L}-\mathrm{Ile}$ ) in a $17 \%$ crude protein diet was shown to improve intestinal immune defense functions with an increase of intestinal immunoglobulins (IgA and SIgA) in weaned piglets [99]. In contrast, some studies also reported that BCAA mixture supplementation $(600 \mathrm{mg} / \mathrm{kg}$ body weight/day, consist of $46 \%$ leucine, $28 \%$ valine, and $23 \%$ isoleucine) could not ameliorate the impaired function of macrophages induced by strenuous exercise in rats [100].

In recent years, there has been growing interest in the role of isoleucine, leucine and valine in immune function (Table 1). Notably, concentrations of isoleucine have a strong correlation with the excretion of $\beta$-defensin. 25 or $50 \mu \mathrm{g} / \mathrm{mL}$ isoleucine increases the mRNA and protein expressions of $\beta$-defensin 1, 2 and 3 in IPEC-J2 cells [101]. Also, treating patients with $250 \mu \mathrm{g}$ of intratracheal L-isoleucine every $48 \mathrm{~h}$ is considered as a novel immunotherapy in tuberculosis as it induced a significant increase of $\beta$-defensins 3 and 4 associated with decreased bacillary loads and tissue damage [102]. This inducing function of isoleucine might be associated with the G-Protein Coupled Receptor and ERK signaling pathways [103]. Additionally, proximally $2 \%$ dietary isoleucine could enhance intestinal immunity in juvenile

Table 1 Branched chain amino acids and immune function

\begin{tabular}{ll}
\hline Amino acid & Regulation of immune function \\
\hline BCAA Mix & $\bullet$ \\
& $\uparrow$ fuel sources for immune cells \\
& $\uparrow$ immune function of neutrophils and lymphocytes \\
& $\bullet$ CD4+, CD4+/CD8+ \\
& $\bullet$ intestinal immunoglobulins \\
Isoleucine & $\bullet$ \\
Leucine & $\uparrow$ excretion of $\beta$-defensin \\
& $\bullet$ regulation of innate and adaptive immune responses \\
& $\bullet$ \\
Valine & $\bullet$ pro-inflammatory cytokines $\downarrow$ anti-inflammatory cytokines \\
& $\uparrow$ dendritic cell function \\
& $\uparrow$ pro-inflammatory cytokines $\downarrow$ anti-inflammatory cytokines
\end{tabular}


Jian carp and innate immunity in olive flounder [104, 105]. Similar functions in regulation of the immune response and antioxidant status in the head kidney were also observed in fish fed about $1.3 \%$ isoleucine [106]. In contrast to isoleucine, leucine regulates the immune system mainly through the mTOR signaling pathway. mTOR plays a vital role in the regulation of the innate and adaptive immune responses and also several immune functions like promoting differentiation, activation, and function in $\mathrm{T}$ cells, $\mathrm{B}$ cells and antigenpresenting cells $[107,108]$. For instance, a reasonable dose of leucine $(40 \mathrm{mg} / \mathrm{mL})$ provides enhanced protective immunity against mucosal infection with herpes simplex virus type 1 [109]. Leucine deficiency could impair the immune status, up-regulate pro-inflammatory cytokines and down-regulate anti-inflammatory cytokines of grass carp (Ctenopharyngodon idella) by the NF- $\mathrm{kB}$ and TOR signaling pathways which was reversed by optimum leucine supplementation [94]. Recently, an in vitro experiment found that an increased extracellular concentration of BCAA, especially valine $(800 \mathrm{nmol} / \mathrm{mL})$, could improve the dendritic cell function in cirrhotic patients [110]. In addition, valine deficiency (less than $1.45 \%$ ) decreased growth and intestinal immune status in young grass carp (Ctenopharyngodon idella) by increasing pro-inflammatory cytokines (IL-8 and TNF- $\alpha$ ) and decreasing anti-inflammatory cytokines (IL-10 and TGF- $\beta 1$ ) which might be caused by changes in the NF-kB and mTOR signaling pathways [111]. However, some studies found there was little effect of valine (increase from $0.64 \%$ to $0.87 \%$ ) on innate or adaptive immunity for broilers [112]. Although still unclear, all these studies are evidence that BCAA may function in improving health and preventing infectious diseases in animals and humans by regulating the immune system.

\section{BCAA, a biomarker for early pathogenesis of chronic diseases}

Obesity is strongly associated with the risk of developing a number of chronic diseases including diabetes, gallstones, hypertension, heart disease and stroke [113]. Scientists have attempted to find biomarkers which can connect the incidence of these diseases via metabolomics. Alterations in their metabolism may play a vital role in the early pathogenesis for humans. Recently, the relationship between metabolomics and obesity (insulinresistant) was revealed by a series of studies [114]. Newgard et al. [15] found that some major components obtained from obese (insulin-resistant) versus lean (insulin sensitive) subjects were different, including long-chain fatty acids, ketone metabolites and mediumchain acylcarnitines, but surprisingly, the component which was most explicitly associated with insulin sensitivity was not the lipid related components mentioned above, but rather was comprised of the BCAA, the aromatic amino acids, C3 and C5 acylcarnitines (Fig. 1), as well as glutamate and alanine. Concurrently, recent metabolomics conducted with 2,422 normoglycemic individuals for $12 \mathrm{yr}$ showed a strong association between metabolite profiles (branched-chain and aromatic amino acids) and future diabetes [115]. In addition, subsequent reports showed that leucine and isoleucine levels (but not valine) are correlated with insulin resistance and blood glucose levels which indicates that analyzing BCAA separately might be better for understanding the association between BCAA and obesity [116]. In study involving twins, BCAA catabolism of the obese was down-regulated compared with lean co-twins in the adipose tissue [117], which could be caused by a decrease of BCATm and BCKD E1 $\alpha$ protein concentrations (first two enzymatic steps of BCAA catabolism)[118]. Studies in animals also strongly support the findings in humans. BCAA metabolism is weak in diabetic mice compared with non-diabetic mice [119]. In addition, high running capacity rats express more BCAA degradation and fatty acid metabolism genes than low running capacity rats [120]. Taken together, elevated BCAA levels in blood (decreased BCAA catabolism) are associated with obesity, diabetes, and other risk factors for metabolic diseases and are a good biomarker for early pathogenesis of these diseases in humans.

\section{Conclusion and perspectives}

BCAA are essential amino acids for animals and humans not only because they cannot be synthesized in the body but also because they display remarkable metabolic and regulatory roles. In humans and animals, BCAA (especially leucine) enhance protein synthesis through the mTOR signaling pathway and now are considered as feed additives to regulate meat quality and are used as performance-enhancing supplements for body builders and fitness enthusiasts. Recently, novel metabolic and physiological functions of BCAA have been reported by scientists. BCAA are metabolic regulators not only in protein synthesis but also in lipid and glucose metabolism. They enhance mammary health, increase milk quality and help in early embryo implantation and development. They improve gut health and its local amino acid transporting ability. They enhance immunity by increasing the expression of $\beta$-defensin, up-regulating pro-inflammatory cytokines and down-regulating antiinflammatory cytokines. Finally, they are biomarkers for early detection of chronic diseases like diabetes and insulin resistance in humans.

A growing body of evidence suggests that food has specific direct and indirect actions to activate intestinal receptors like a cocktail of 'hormones' [121]. This 
activation can increase the secretion of GI tract hormones like peptide YY (PYY), glucagon-like peptide 1 (GLP-1) and cholecystokinin (CCK) [122]. There are variety of receptors in the GI tract for amino acids which have been discovered such as T1R1/T1R3, CaSR, GPCR6A and mGluR [123]. The activation of these receptors might participate in the regulation of food intake, proliferation of GI cells, small intestinal motility and neural reflexes [124]. However, the specific receptors for BCAA are still a mystery and wait to be discovered. Knowing the receptors of BCAA is vital for a better understanding of the physiological roles of BCAA.

In the future, with the help of high throughput functional genomics, metabolomics, and proteomics, the underlying functions of BCAA in gene, protein expression and metabolic regulation will be revealed. The effects of the BCAA on microbe numbers can be analyzed by $16 \mathrm{~S}$ targeted sequencing and metagenomic sequencing. All of these techniques will help in interpreting the complex and inconsistent results obtained to date and largely expand our vision of the novel functions of BCAA in humans and animals.

\section{Acknowledgements}

The author would like to thank Dr. M. A. Brown and Dr. P. A. Thacker for their help.

\section{Funding}

This work was supported by the National Key Basic Research Program (S.Y.Q., Grant Number 2012CB124704).

\section{Availability of data and materials}

Not applicable.

\section{Authors' contributions}

SZ initiated the idea, the scope, and the outline of this review paper. SZ, MR, $X \mathrm{M}, \mathrm{SQ}$ and $\mathrm{XZ}$ studied and analyzed all of the publications cited in this paper and were involved in the manuscript preparation. XZ conducted the final editing and proofreading. All authors read and approved the final manuscript.

\section{Competing interests}

The authors declare that they have no competing interests.

\section{Consent for publication}

Not applicable.

\section{Ethics approval}

All procedures used in experiments of our lab were performed in accordance with the China Agricultural University Animal Care and Use Committee guidelines (ID: SKLAB-B-2010-003).

\footnotetext{
Author details

${ }^{1}$ State Key Laboratory of Animal Nutrition, College of Animal Science and Technology, China Agricultural University, No.2 Yuanmingyuan West Road, Haidian District, Beijing 100193, People's Republic of China. ${ }^{2}$ College of Animal Science, South China Agricultural University, Wushan Avenue, Tianhe District, Guangzhou 510642, People's Republic of China. ${ }^{3}$ College of Animal Science, Anhui Science \& Technology University, No. 9 Donghua Road, Fengyang 233100, Anhui Province, People's Republic of China. ${ }^{4}$ Animal Nutrition Institute, Key Laboratory of Animal

Disease-ResistanceNutrition,Ministry of Education, Sichuan

AgriculturalUniversity, Ya'an, Sichuan, China.
}

Received: 26 July 2016 Accepted: 27 December 2016

Published online: 23 January 2017

\section{References}

1. Wu G. Functional amino acids in nutrition and health. Amino Acids. 2013;45:407-11.

2. Freund $\mathrm{H}$, Yoshimura $\mathrm{N}$, Lunetta $\mathrm{L}$, Fischer J. The role of the branched-chain amino acids in decreasing muscle catabolism in vivo. Surgery. 1978:83:611-8.

3. Hedden MP, Buse MG. General stimulation of muscle protein synthesis by branched chain amino acids in vitro. Exp Biol Med. 1979;160:410-5.

4. Lemon PW. Protein and amino acid needs of the strength athlete. Int J Sport Nutr. 1991;1:127-45.

5. Norton LE, Layman DK. Leucine regulates translation initiation of protein synthesis in skeletal muscle after exercise. J Nutr. 2006;136:533S-7S.

6. Nair KS, Short KR. Hormonal and signaling role of branched-chain amino acids. J Nutr. 2005;135:1547S-52S.

7. Tanti JF, Jager J. Cellular mechanisms of insulin resistance: role of stressregulated serine kinases and insulin receptor substrates (IRS) serine phosphorylation. Curr Opin Pharmacol. 2009;9:753-62.

8. Abdalla SAS, Elfaghi R. A perspective on interaction between lipid and branched chain amino acids (BCAA) in developing insulin resistance. Medicine. 2014;1:8-12.

9. Negro M, Giardina S, Marzani B, Marzatico F. Branched-chain amino acid supplementation does not enhance athletic performance but affects muscle recovery and the immune system. J Sports Med Phys Fitness. 2008:48:347-51.

10. Teodoro GFR, Vianna D, Torres-Leal FL, Pantaleão LC, Matos-Neto EM, Donato J, et al. Leucine is essential for attenuating fetal growth restriction caused by a protein-restricted diet in rats. J Nutr. 2012;142:924-30.

11. Lei J, Feng D, Zhang Y, Dahanayaka S, Li X, Yao K, et al. Regulation of leucine catabolism by metabolic fuels in mammary epithelial cells. Amino Acids. 2012;43:2179-89.

12. Li P, Knabe DA, Kim SW, Lynch CJ, Hutson SM, Wu G. Lactating porcine mammary tissue catabolizes branched-chain amino acids for glutamine and aspartate synthesis. J Nutr. 2009;139:1502-9.

13. Nishimura J, Masaki T, Arakawa M, Seike M, Yoshimatsu H. Isoleucine prevents the accumulation of tissue triglycerides and upregulates the expression of PPARa and uncoupling protein in diet-induced obese mice. J Nutr. 2010;140:496-500.

14. Doi M, Yamaoka I, Fukunaga T, Nakayama M. Isoleucine, a potent plasma glucose-lowering amino acid, stimulates glucose uptake in C2C12 myotubes. Biochem Biophys Res Commun. 2003;312:1111-7.

15. Newgard CB, An J, Bain JR, Muehlbauer MJ, Stevens RD, Lien LF, et al. A branched-chain amino acid-related metabolic signature that differentiates obese and lean humans and contributes to insulin resistance. Cell Metab. 2009;9:311-26.

16. Kainulainen $\mathrm{H}$, Hulmi JJ, Kujala UM. Potential role of branched-chain amino acid catabolism in regulating fat oxidation. Exerc Sport Sci Rev. 2013;41:194200.

17. Layman DK, Boileau RA, Erickson DJ, Painter JE, Shiue H, Sather C, et al. A reduced ratio of dietary carbohydrate to protein improves body composition and blood lipid profiles during weight loss in adult women. J Nutr. 2003;133:411-7.

18. Noakes M, Keogh JB, Foster PR, Clifton PM. Effect of an energy-restricted, high-protein, low-fat diet relative to a conventional high-carbohydrate, lowfat diet on weight loss, body composition, nutritional status, and markers of cardiovascular health in obese women. Am J Clin Nutr. 2005;81:1298-306.

19. Crozier SJ, Kimball SR, Emmert SW, Anthony JC, Jefferson LS. Oral leucine administration stimulates protein synthesis in rat skeletal muscle. J Nutr. 2005;135:376-82.

20. Guo F, Cavener DR. The GCN2 elF2a kinase regulates fatty-acid homeostasis in the liver during deprivation of an essential amino acid. Cell Metab. 2007;5:103-14.

21. Cheng Y, Meng Q, Wang C, Li H, Huang Z, Chen S, et al. Leucine deprivation decreases fat mass by stimulation of lipolysis in white adipose tissue and upregulation of uncoupling protein 1 (UCP1) in brown adipose tissue. Diabetes. 2010;59:17-25.

22. Du Y, Meng Q, Zhang Q, Guo F. Isoleucine or valine deprivation stimulates fat loss via increasing energy expenditure and regulating lipid metabolism in WAT. Amino Acids. 2012;43:725-34. 
23. Bai J, Greene E, Li W, Kidd MT, Dridi S. Branched-chain amino acids modulate the expression of hepatic fatty acid metabolism-related genes in female broiler chickens. Mol Nutr Food Res. 2015;59:1171-81.

24. Bernard JR, Liao YH, Doerner PG, Ding Z, Hsieh M, Wang W, et al. An amino acid mixture is essential to optimize insulin-stimulated glucose uptake and GLUT4 translocation in perfused rodent hindlimb muscle. J Appl Physio. 2012:113:97-104

25. Nishitani S, Takehana K, Fujitani S, Sonaka I. Branched-chain amino acids improve glucose metabolism in rats with liver cirrhosis. Am J Physiol Gastrointest Liver Physiol. 2005;288:G1292-300

26. Doi M, Yamaoka I, Nakayama M, Mochizuki S, Sugahara K, Yoshizawa F. Isoleucine, a blood glucose-lowering amino acid, increases glucose uptake in rat skeletal muscle in the absence of increases in AMP-activated protein kinase activity. J Nutr. 2005;135:2103-8.

27. Doi M, Yamaoka I, Nakayama M, Sugahara K, Yoshizawa F. Hypoglycemic effect of isoleucine involves increased muscle glucose uptake and whole body glucose oxidation and decreased hepatic gluconeogenesis. Am J Physiol Endocrinol Metab. 2007;292:E1683-93.

28. Li C, Najafi H, Daikhin Y, Nissim IB, Collins HW, Yudkoff M, et al. Regulation of leucine-stimulated insulin secretion and glutamine metabolism in isolated rat islets. J Biol Chem. 2003:278:2853-8.

29. Lund S, Holman G, Schmitz O, Pedersen O. Contraction stimulates translocation of glucose transporter GLUT4 in skeletal muscle through a mechanism distinct from that of insulin. Proc Natl Acad Sci U S A. 1995;92:5817-21.

30. Koivisto U-M, Martinez-Valdez H, Bilan P, Burdett E, Ramlal T, Klip A. Differential regulation of the GLUT-1 and GLUT-4 glucose transport systems by glucose and insulin in L6 muscle cells in culture. J Biol Chem. 1991;266:2615-21.

31. Chen HC, Bandyopadhyay G, Sajan MP, Kanoh Y, Standaert M, Farese RV. Activation of the ERK pathway and atypical protein kinase $C$ isoforms in exercise-and aminoimidazole-4-carboxamide-1- $\beta$-d-riboside (AICAR)stimulated glucose transport. J Biol Chem. 2002;277:23554-62.

32. Zhang SH, Yang Q, Ren M, Qiao SY, He PL, Li DF, et al. Effects of isoleucine on glucose uptake through the enhancement of muscular membrane concentrations of GLUT1 and GLUT4 and intestinal membrane concentrations of $\mathrm{Na}^{+}$/glucose co-transporter 1 (SGLT-1) and GLUT2. Br J Nutr. 2016;116:593-602.

33. Anthony JC, Anthony TG, Layman DK. Leucine supplementation enhances skeletal muscle recovery in rats following exercise. J Nutr. 1999:129:1102-6.

34. Anthony JC, Yoshizawa F, Anthony TG, Vary TC, Jefferson LS, Kimball SR. Leucine stimulates translation initiation in skeletal muscle of postabsorptive rats via a rapamycin-sensitive pathway. J Nutr. 2000;130:2413-9.

35. Anthony JC, Anthony TG, Kimball SR, Vary TC, Jefferson LS. Orally administered leucine stimulates protein synthesis in skeletal muscle of postabsorptive rats in association with increased elF4F formation. J Nutr 2000;130:139-45

36. Bolster DR, Vary TC, Kimball SR, Jefferson LS. Leucine regulates translation initiation in rat skeletal muscle via enhanced elF4G phosphorylation. J Nutr. 2004;134:1704-10.

37. Koopman R, Wagenmakers A, Manders R, Antoine H, Joan M, Marchel G, et al. Combined ingestion of protein and free leucine with carbohydrate increases postexercise muscle protein synthesis in vivo in male subjects. Am J Physiol Endocrinol Metabo. 2005;288:E645-53.

38. Anthony JC, Reiter AK, Anthony TG, Crozier SJ, Lang CH, MacLean DA, et al. Orally administered leucine enhances protein synthesis in skeletal muscle of diabetic rats in the absence of increases in 4E-BP1 or S6K1 phosphorylation. Diabetes. 2002;51:928-36.

39. Escobar J, Frank JW, Suryawan A, Nguyen HV, Kimball SR, Jefferson LS, et al. Physiological rise in plasma leucine stimulates muscle protein synthesis in neonatal pigs by enhancing translation initiation factor activation. Am J Physiol Endocrinol Metab. 2005;288:E914-21.

40. Suryawan A, Jeyapalan AS, Orellana RA, Wilson FA, Nguyen HV, Davis TA. Leucine stimulates protein synthesis in skeletal muscle of neonatal pigs by enhancing mTORC1 activation. Am J Physiol Endocrinol Metab. 2008;295:E868-75.

41. Davis TA, Fiorotto ML, Burrin DG, Reeds PJ, Nguyen HV, Beckett PR, et al. Stimulation of protein synthesis by both insulin and amino acids is unique to skeletal muscle in neonatal pigs. Am J Physiol Endocrinol Metab. 2002;282:E880-90.

42. Drummond MJ, Rasmussen BB. Leucine-enriched nutrients and the regulation of mammalian target of rapamycin signalling and human skeletal muscle protein synthesis. Curr Opin Clin Nutr Metab Care. 2008; 11:222-6.
43. Koopman R, Wagenmakers AJ, Manders RJ, Zorenc AH, Senden JM, Gorselink M, et al. Combined ingestion of protein and free leucine with carbohydrate increases postexercise muscle protein synthesis in vivo in male subjects. Am J Physiol Endocrinol Metab. 2005;288:E645-53.

44. Escobar J, Frank JW, Suryawan A, Nguyen HV, Van Horn CG, Hutson SM, et al. Leucine and a-ketoisocaproic acid, but not norleucine, stimulate skeletal muscle protein synthesis in neonatal pigs. J Nutr. 2010;140:1418-24.

45. Escobar J, Frank JW, Suryawan A, Nguyen HV, Davis TA. Amino acid availability and age affect the leucine stimulation of protein synthesis and elF4F formation in muscle. Am J Physiol Endocrinol Metab. 2007;293:E1615-21.

46. Boutry C, El-Kadi SW, Suryawan A, Wheatley SM, Orellana RA, Kimball SR et al. Leucine pulses enhance skeletal muscle protein synthesis during continuous feeding in neonatal pigs. Am J Physiol Endocrinol Metab. 2013:305:E620-31.

47. Torrazza RM, Suryawan A, Gazzaneo MC, Orellana RA, Frank JW, Nguyen HV, et al. Leucine supplementation of a low-protein meal increases skeletal muscle and visceral tissue protein synthesis in neonatal pigs by stimulating mTOR-dependent translation initiation. J Nutr. 2010;140:2145-52.

48. Manjarín R, Columbus DA, Suryawan A, Nguyen HV, Hernandez-García AD, Hoang NM, et al. Leucine supplementation of a chronically restricted protein and energy diet enhances mTOR pathway activation but not muscle protein synthesis in neonatal pigs. Amino Acids. 2016;48:257-67.

49. Wilson FA, Suryawan A, Gazzaneo MC, Orellana RA, Nguyen HV, Davis TA. Stimulation of muscle protein synthesis by prolonged parenteral infusion of leucine is dependent on amino acid availability in neonatal pigs. J Nutr. 2010;140:264-70.

50. Mao X, Zeng X, Wang J, Qiao S. Leucine promotes leptin receptor expression in mouse C2C12 myotubes through the mTOR pathway. Mol Biol Rep. 2011;38:3201-6.

51. Mao X, Zeng X, Huang Z, Wang J, Qiao S. Leptin and leucine synergistically regulate protein metabolism in C2C12 myotubes and mouse skeletal muscles. Br J Nutr. 2013;110:256-64.

52. Zhang S, Chu L, Qiao S, Mao X, Zeng X. Effects of dietary leucine supplementation in low crude protein diets on performance, nitrogen balance, whole-body protein turnover, carcass characteristics and meat quality of finishing pigs. Anim Sci J. 2016;87:911-20.

53. Madeira M, Alfaia C, Costa P, Lopes $P$, Lemos J, Bessa R, et al. The combination of arginine and leucine supplementation of reduced crude protein diets for boars increases eating quality of pork. J Anim Sci. 2014;92: 2030-40.

54. Wessels AG, Kluge H, Hirche F, Kiowski A, Schutkowski A, Corrent E, et al. High Leucine Diets Stimulate Cerebral Branched-Chain Amino Acid Degradation and Modify Serotonin and Ketone Body Concentrations in a Pig Model. PLoS One. 2016;11:e0150376.

55. Koch CE, Göddeke S, Krüger M, Tups A. Effect of central and peripheral leucine on energy metabolism in the Djungarian hamster (Phodopus sungorus). J Comp Physiol B. 2012;183:261-8.

56. Laeger T, Reed SD, Henagan TM, Fernandez DH, Taghavi M, Addington A, et al. Leucine acts in the brain to suppress food intake but does not function as a physiological signal of low dietary protein. Am J Physiol Regul Integr Comp Physiol. 2014;307:R310-20.

57. Cota D, Proulx K, Smith KA, Kozma SC, Thomas G, Woods SC, et al. Hypothalamic mTOR signaling regulates food intake. Science. 2006:312:927-30.

58. Dardevet D, Sornet C, Bayle G, Prugnaud J, Pouyet C, Grizard J. Postprandial stimulation of muscle protein synthesis in old rats can be restored by a leucine-supplemented meal. J Nutr. 2002;132:95-100.

59. Rieu I, Sornet C, Bayle G, Prugnaud J, Pouyet C, Balage M, et al. Leucinesupplemented meal feeding for ten days beneficially affects postprandial muscle protein synthesis in old rats. J Nutr. 2003;133:1198-205.

60. Bassil MS, Hwalla N, Obeid OA. Meal pattern of male rats maintained on histidine-, leucine-, or tyrosine-supplemented diet. Obesity. 2007;15:616-23.

61. Pedrosa RG, Jr DJ, Pires IS, Tirapegui J. Leucine supplementation increases serum insulin-like growth factor 1 concentration and liver protein/RNA ratio in rats after a period of nutritional recovery. Appl Physiol Nutr Metab. 2013;38:694-7.

62. Gloaguen $M$, Le FHN, Corrent E, Primot $Y$, Van MJ. Providing a diet deficient in valine but with excess leucine results in a rapid decrease in feed intake and modifies the postprandial plasma amino acid and a-keto acid concentrations in pigs. J Anim Sci. 2012;90:3135-42. 
63. Zhang S, Qiao S, Ren M, Zeng X, Ma X, Wu Z, et al. Supplementation with branched-chain amino acids to a low-protein diet regulates intestinal expression of amino acid and peptide transporters in weanling pigs. Amino Acids. 2013:45:1191-205.

64. Anthony TG, Gietzen DW. Detection of amino acid deprivation in the central nervous system. Curr Opin Clin Nutr Metab Care. 2013;16:96-101.

65. DeSantiago S, Torres N, Suryawan A, Tovar AR, Hutson SM. Regulation of branchedchain amino acid metabolism in the lactating rat. J Nutr. 1998;128:1165-71.

66. DeSantiago S, Torres N, Tovar AR. Leucine catabolism in mammary tissue, liver and skeletal muscle of dam rat during lactation and weaning. Arch Med Res. 1997;29:25-32.

67. Matsumoto T, Nakamura E, Nakamura H, Hirota M, San Gabriel A, Nakamura $\mathrm{K}-\mathrm{i}$, et al. Production of free glutamate in milk requires the leucine transporter LAT1. Am J Physiol Cell Physiol. 2013;305:C623-31.

68. DeSantiago S, Torres N, Hutson S, Tovar AR. Induction of expression of branched-chain aminotransferase and alpha-keto acid dehydrogenase in rat tissues during lactation. Adv Exp Med Biol. 2001:501:93-9.

69. Lei J, Feng D, Zhang Y, Dahanayaka S, Li X, Yao K, et al. Hormonal regulation of leucine catabolism in mammary epithelial cells. Amino Acids. 2013;45:531-41.

70. Dunshea FR, Bauman DE, Nugent EA, Kerton DJ, King RH, McCauley I. Hyperinsulinaemia, supplemental protein and branched-chain amino acids when combined can increase milk protein yield in lactating sows. Br J Nutr. 2005; $93: 325-32$

71. Doelman J, Curtis RV, Carson M, Kim JJM, Cant JP, Metcalf JA. Milk protein synthesis is regulated by lysine and branched chain amino acid deficiencies in lactating bovine mammary glands. J Dairy Sci. 2014;97(E-Suppl 1):205.

72. Strathe AV, Bruun TS, Zerrahn JE, Tauson AH, Hansen CF. The effect of increasing the dietary valine-to-lysine ratio on sow metabolism, milk production, and litter growth. J Anim Sci. 2016;94:155-64.

73. Doelman J, Kim JJ, Carson M, Metcalf JA, Cant JP. Branched-chain amino acid and lysine deficiencies exert different effects on mammary translational regulation. J Dairy Sci. 2015;98:7846-55.

74. Moser S, Tokach M, Dritz S, Goodband R, Nelssen J, Loughmiller J. The effects of branched-chain amino acids on sow and litter performance. J Anim Sci. 2000;78:658-67.

75. Lei J, Feng D, Zhang Y, Zhao FQ, Wu Z, San Gabriel A, et al. Nutritional and regulatory role of branched-chain amino acids in lactation. Front Biosci. 2012;17:725-2

76. Appuhamy JRN, Knoebel NA, Nayananjalie WD, Escobar J, Hanigan MD. Isoleucine and leucine independently regulate mTOR signaling and protein synthesis in MACT cells and bovine mammary tissue slices. J Nutr. 2012;142:484-91.

77. Rezaei R. Nutritional and Regulatory Roles for Branched-Chain Amino Acids in Milk Production by Lactating Sows. 2015. Texas A \& M University. Available electronically from http://oaktrust.library.tamu.edu/handle/1969.1/ 154999. Accessed 26 Jan 2015.

78. Desai M, Gayle D, Babu J, Ross MG. Permanent reduction in heart and kidney organ growth in offspring of undernourished rat dams. Am J Obstet Gynecol. 2005;193:1224-32.

79. Mogami H, Yura S, Itoh H, Kawamura M, Fujii T, Suzuki A, et al. Isocaloric high-protein diet as well as branched-chain amino acids supplemented diet partially alleviates adverse consequences of maternal undernutrition on fetal growth. Growth Horm IGF Res. 2009;19:478-85.

80. Lynch CJ, Fox HL, Vary TC, Jefferson LS, Kimball SR. Regulation of amino acid-sensitive TOR signaling by leucine analogues in adipocytes. J Cell Biochem. 2000;77:234-51.

81. Mawatari K, Katsumata T, Uematsu M, Katsumata T, Yoshida J, Smriga M, et al. Prolonged oral treatment with an essential amino acid L-leucine does not affect female reproductive function and embryo-fetal development in rats. Food Chem Toxicol. 2004;42:1505-11.

82. Spindle A. An improved culture medium for mouse blastocysts. In Vitro. 1980;16:669-74

83. Martin PM, Sutherland AE. Exogenous amino acids regulate trophectoderm differentiation in the mouse blastocyst through an mTOR-dependent pathway. Dev Biol. 2001;240:182-93.

84. Gangloff YG, Mueller M, Dann SG, Svoboda P, Sticker M, Spetz J-F, et al. Disruption of the mouse mTOR gene leads to early postimplantation lethality and prohibits embryonic stem cell development. Mol Cell Biol. 2004;24:9508-16.

85. Guertin DA, Stevens DM, Thoreen CC, Burds AA, Kalaany NY, Moffat J, et al. Ablation in mice of the $\mathrm{MTORC}$ components raptor, rictor, or $\mathrm{mLST} 8$ reveals that mTORC2 is required for signaling to Akt-FOXO and PKCa, but not S6K1. Dev Cell. 2006;11:859-71.

86. González IM, Martin PM, Burdsal C, Sloan JL, Mager S, Harris T, et al. Leucine and arginine regulate trophoblast motility through mTOR-dependent and independent pathways in the preimplantation mouse embryo. Dev Biol. 2012;361:286-300.

87. Van Winkle LJ. Amino acid transport regulation and early embryo development. Biol Reprod. 2001;64:1-12.

88. Chen L, Yin YL, Jobgen WS, Jobgen SC, Knabe DA, Hu WX, et al. In vitro oxidation of essential amino acids by jejunal mucosal cells of growing pigs. Livest Sci. 2007;109:19-23.

89. Chen L, Li P, Wang J, Li X, Gao H, Yin Y, et al. Catabolism of nutritionally essential amino acids in developing porcine enterocytes. Amino Acids. 2009;37:143-52.

90. Sun Y, Wu Z, Li W, Zhang C, Sun K, Ji Y, et al. Dietary l-leucine supplementation enhances intestinal development in suckling piglets. Amino Acids. 2015:47:1517-25.

91. Zhang S, Ren M, Zeng X, He P, Ma X, Qiao S. Leucine stimulates ASCT2 amino acid transporter expression in porcine jejunal epithelial cell line (IPEC-J2) through PI3K/Akt/mTOR and ERK signaling pathways. Amino Acids. 2014;46:2633-42.

92. Chang Y, Cai H, Liu G, Chang W, Zheng A, Zhang S, et al. Effects of dietary leucine supplementation on the gene expression of mammalian target of rapamycin signaling pathway and intestinal development of broilers. Animal Nutrition. 2015;1:313-9.

93. Mao X, Liu M, Tang J, Chen H, Chen D, Yu B, et al. Dietary leucine supplementation improves the mucin production in the jejunal mucosa of the weaned pigs challenged by porcine rotavirus. PLoS One. 2015;10: e0137380.

94. Jiang WD, Deng YP, Liu Y, Qu B, Jiang J, Kuang SY, et al. Dietary leucine regulates the intestinal immune status, immune-related signalling molecules and tight junction transcript abundance in grass carp (Ctenopharyngodon idella). Aquaculture. 2015;444:134-42.

95. Dai ZL, Zhang J, Wu G, Zhu WY. Utilization of amino acids by bacteria from the pig small intestine. Amino Acids. 2010;39:1201-15.

96. Nakamura I. Impairment of innate immune responses in cirrhotic patients and treatment by branched-chain amino acids. World J Gastroenterol. 2014;20:7298.

97. Zhang W, Feng F, Wang WZ, Li MB, Ji G, Guan C. The effects of BCAAenriched amino acid solution on immune function and protein metabolism in postoperative patients with rectal cancer. Parenteral \& Enteral Nutrition. 2007;2:009.

98. Kephart WC, Wachs TD, Mac Thompson R, Mobley CB, Fox CD, McDonald $J R$, et al. Ten weeks of branched-chain amino acid supplementation improves select performance and immunological variables in trained cyclists. Amino Acids. 2016:48:779-89.

99. Ren M, Zhang S, Zeng X, Liu H, Qiao S. Branched-chain amino acids are beneficial to maintain growth performance and intestinal immune-related function in weaned piglets fed protein restricted diet. Asian-Australas J Anim Sci. 2015:28:1742.

100. Xiao W, Chen P, Liu X, Zhao L. The impaired function of macrophages induced by strenuous exercise could not be ameliorated by BCAA supplementation. Nutrients. 2015;7:8645-56.

101. Mao X, Qi S, Yu B, He J, Yu J, Chen D. Zn ${ }^{2+}$ and l-isoleucine induce the expressions of porcine $\beta$-defensins in IPEC-J2 cells. Mol Biol Rep. 2013:40:1547-52.

102. Rivas-Santiago C, Rivas-Santiago B, León D, Castañeda-Delgado J, Hernández PR. Induction of $\beta$-efensins by l-isoleucine as novel immunotherapy in experimental murine tuberculosis. Clin Exp Immunol. 2011;164:80-9.

103. Youkou K, Toshifumi A, Yuhei I, Takahiro I, Hiroki T, Atsuo M, et al. Isoleucine, an essential amino acid, induces the expression of human $\beta$ defensin 2 through the activation of the G-protein coupled receptor-ERK pathway in the intestinal epithelia. Food Nutr Sci. 2012. doi:10.4236/fns.2012.34077.

104. Zhao J, Feng L, Liu Y, Jiang W, Wu P, Jiang J, et al. Effect of dietary isoleucine on the immunity, antioxidant status, tight junctions and microflora in the intestine of juvenile Jian carp (Cyprinus carpio var. Jian). Fish Shellfish Immunol. 2014:41:663-73.

105. Rahimnejad S, Lee KJ. Dietary Isoleucine Influences Non-Specific Immune Response in Juvenile Olive Flounder (Paralichthys olivaceus). Turk J Fish Aquat Sci. 2014;14:853-62.

106. Zhao J, Liu Y, Jiang J, Wu P, Jiang W, Li S, et al. Effects of dietary isoleucine on the immune response, antioxidant status and gene expression in the 
head kidney of juvenile Jian carp (Cyprinus carpio var. Jian). Fish Shellfish Immunol. 2013;35:572-80.

107. Powell JD, Pollizzi KN, Heikamp EB, Horton MR. Regulation of immune responses by mTOR. Annu Rev Immunol. 2012;30:39.

108. Soliman GA. The role of mechanistic target of rapamycin (mTOR) complexes signaling in the immune responses. Nutrients. 2013;5:2231-57.

109. Uyangaa E, Lee HK, Eo SK. Glutamine and leucine provide enhanced protective immunity against mucosal infection with herpes simplex virus type 1. Immune Netw. 2012;12:196-206.

110. Kakazu E, Kanno N, Ueno Y, Shimosegawa T. Extracellular branched-chain amino acids, especially valine, regulate maturation and function of monocyte-derived dendritic cells. J Immunol. 2007;179:7137-46.

111. Luo J-B, Feng L, Jiang W-D, Liu Y, Wu P, Jiang J, et al. The impaired intestinal mucosal immune system by valine deficiency for young grass carp (Ctenopharyngodon idella) is associated with decreasing immune status and regulating tight junction proteins transcript abundance in the intestine. Fish Shellfish Immunol. 2014;40:197-207.

112. Thornton SA, Corzo A, Pharr G, Dozier lii W, Miles D, Kidd M. Valine requirements for immune and growth responses in broilers from 3 to 6 weeks of age. Br Poult Sci. 2006;47:190-9.

113. Field AE, Coakley EH, Must A, Spadano JL, Laird N, Dietz WH, et al. Impact of overweight on the risk of developing common chronic diseases during a 10-year period. Arch Intern Med. 2001;161:1581-6.

114. McCormack SE, Shaham O, McCarthy MA, Deik AA, Wang TJ, Gerszten RE, et al. Circulating branched-chain amino acid concentrations are associated with obesity and future insulin resistance in children and adolescents. Pediatr Obes. 2013;8:52-61.

115. Wang TJ, Larson MG, Vasan RS, Cheng S, Rhee EP, McCabe E, et al. Metabolite profiles and the risk of developing diabetes. Nat Med. 2011;17:448-53.

116. Allam-Ndoul B, Guénard F, Garneau V, Barbier O, Pérusse L, Vohl MC Associations between branched chain amino acid levels, obesity and cardiometabolic complications. Integr Obesity Diabetes. 2015. doi: 10.15761//OD.1000134

117. Pietiläinen KH, Naukkarinen J, Rissanen A, Saharinen J, Ellonen P, Keränen H, et al. Global transcript profiles of fat in monozygotic twins discordant for BMI: pathways behind acquired obesity. PLoS Med. 2008;5:e51.

118. She P, Van Horn C, Reid T, Hutson SM, Cooney RN, Lynch CJ. Obesity-related elevations in plasma leucine are associated with alterations in enzymes involved in branched-chain amino acid metabolism. Am J Physiol Endocrinol Metab. 2007;293:E1552-63.

119. Connor SC, Hansen MK, Corner A, Smith RF, Ryan TE. Integration of metabolomics and transcriptomics data to aid biomarker discovery in type 2 diabetes. Mol Biosyst. 2010;6:909-21.

120. Kivelä R, Silvennoinen M, Lehti M, Rinnankoski-Tuikka R, Purhonen T, Ketola $T$, et al. Gene expression centroids that link with low intrinsic aerobic exercise capacity and complex disease risk. The FASEB J. 2010;24:4565-74.

121. Ryan KK, Seeley RJ. Food as a hormone. Science. 2013;339:918.

122. Cummings DE, Overduin J. Gastrointestinal regulation of food intake. J Clin Invest. 2007:117:13-23.

123. Brennan SC, Davies TS, Schepelmann M, Riccardi D. Emerging roles of the extracellular calcium-sensing receptor in nutrient sensing: control of taste modulation and intestinal hormone secretion. Br J Nutr. 2014;111:S16-22.

124. Rozengurt E, Sternini C. Taste receptor signaling in the mammalian gut. Curr Opin Pharmacol. 2007;7:557-62.

\section{Submit your next manuscript to BioMed Centra and we will help you at every step:}

- We accept pre-submission inquiries

- Our selector tool helps you to find the most relevant journal

- We provide round the clock customer support

- Convenient online submission

- Thorough peer review

- Inclusion in PubMed and all major indexing services

- Maximum visibility for your research

Submit your manuscript at www.biomedcentral.com/submit

C Biomed Central 